\title{
History of medication-assisted treatment and its association with initiating others into injection drug use in San Diego, CA
}

Maria Luisa Mittal', Devesh Vashishtha', Shelly Sun², Sonia Jain², Jazmine Cuevas-Mota', Richard Garfein', Steffanie A. Strathdee ${ }^{1}$ and Dan Werb ${ }^{1 *}$

\begin{abstract}
Background: Medication-assisted treatment (MAT) remains the gold standard for the treatment of opioid use disorder. MAT also reduces the frequency of injecting among people who inject drugs (PWID). Relatedly, data suggest that PWID play a key role in the initiation of others into drug injecting by exposing injecting practices to injection-naive drug users. Our primary objective was to test whether a history of MAT enrollment is associated with a reduced odds of PWID providing injection initiation assistance.

Methods: Preventing Injecting by Modifying Existing Responses (PRIMER; NIDA DP2-DA040256-01), is a multi-site cohort study assessing the impact of socio-structural factors on the risk that PWID provide injection initiation assistance. Data were drawn from a participating cohort of PWID in San Diego, CA. The primary outcome was reporting ever providing injection initiation assistance; the primary predictor was reporting ever being enrolled in MAT. Logistic regression was used to model associations between MAT enrollment and ever initiating others into injecting while adjusting for potential confounders.

Results: Participants ( $n=354)$ were predominantly male $(n=249,70 \%)$. Thirty-eight percent $(n=135)$ of participants reported ever initiating others into injection drug use. In multivariate analysis, participants who reported a history of MAT enrollment had significantly decreased odds of ever providing injection initiation assistance (Adjusted Odds Ratio [AOR]: 0.62, 95\% Confidence Interval [Cl]: 0.39-0.99).

Conclusions: These preliminary findings suggest an association between MAT enrollment and a lower odds that male PWID report providing injection initiation assistance to injection-naive drug users. Further research is needed to identify the pathways by which MAT enrollment may impact the risk that PWID initiate others into drug injecting.
\end{abstract}

Keywords: Opioid substitution therapy, HIV prevention, HCV prevention, People who inject drugs, Methadone, Opioid agonist treatment, Injection initiation assistance

\section{Background}

Medication-assisted treatment (MAT) remains the gold standard of biomedical care for opioid use disorder, and is effective in reducing the frequency of injecting among people who inject drugs (PWID) [1-4]. This is important given the growing scientific consensus that PWID play a key role in the expansion of injection-related

\footnotetext{
* Correspondence: dwerb@ucsd.edu

'Division of Infectious Diseases and Global Public Health, Department of Medicine, University of California San Diego, 9500 Gilman Drive, La Jolla, CA 92093-0507, USA

Full list of author information is available at the end of the article
}

epidemics by exposing and directly initiating injectionnaive persons into injection drug use (IDU) $[5,6]$. With an estimated 12 million PWID worldwide, and an increasing prevalence of opioid-related morbidity and mortality in North America and elsewhere, the prevention of opioid IDU initiation (e.g. heroin) has major public health implications $[1,2,7,8]$. This is particularly the case as the period immediately following IDU initiation has been shown to be associated with a higher risk of HIV and HCV acquisition [9].

MAT includes opioid agonist treatment (i.e., methadone; also known as opioid substitution therapy), in combination 
with counseling and behavioral therapies to treat opioid use disorder [1-4]. Given that MAT is associated with reductions in the frequency of opioid injecting among PWID as well as street-based injecting in particular, we hypothesize that MAT enrollment may have a secondary preventive impact on the risk that PWID expose and initiate others into injecting [3-10]. This study therefore investigated the potential association between a history of MAT enrollment and reporting injection initiation assistance among PWID.

\section{Methods}

\section{Study design}

Preventing Injecting by Modifying Existing Responses (PRIMER; NIDA DP2-DA040256-01), is a multi-site study pooling data from cohort studies of PWID in four countries (San Diego, USA; Tijuana, Mexico; Vancouver, Canada; and Paris, Marseille, Bordeaux and Strasbourg, France) to assess the impact of socio-structural factors on the risk that PWID initiate others into injection [5]. For the present analysis, data were drawn from a cohort study of PWID in San Diego, California (Study of Tuberculosis, AIDS, and Hepatitis C Risk [STAHR] II; NIDA R01DA031074). To be eligible, participants had to be $\geq 18$ years old, report last IDU $\leq 30$ days prior to baseline enrollment.

\section{Participants and measures}

Participants completed an interviewer-administered questionnaire assessing sociodemographics, IDU practices, and enrollment in health services including MAT (i.e., methadone) at baseline and at four semiannual follow-up visits. Specific questions related to providing injection initiation assistance were introduced as part of the PRIMER study at the 24-month follow-up wave (i.e., August 2014). Participants provided written informed consent. This study was approved by the University of California San Diego Human Research Protection Program.

Twenty-four month follow-up data were employed in cross-sectional analyses because PRIMER study questions were anchored at this visit. The primary outcome was reporting ever initiating others into IDU, (i.e., reporting having "ever helped someone inject who had never injected before"). The primary predictor of interest was a history of MAT enrollment defined as at least one report of MAT enrollment during any study visit.

\section{Statistical analyses}

Fisher's exact test was used to evaluate univariate associations between ever initiating others into IDU and the independent variables. Multivariate logistic regression analysis was performed to determine whether reporting ever initiating others was associated with ever being enrolled in MAT, independent of potential confounders such as age, gender, and years since first injection. We also studied interactions between gender and MAT enrollment in a separate multivariate model, given previous data suggesting gender differences in injection initiation risk behaviors [6, 11-15]. Statistical analyses were performed in $\mathrm{R}$ version 3.1.1 (http://www.r-project.org). The likelihood ratio statistic (LRS) was used to compare nested models; LRS with $p<0.05$ were used to determine whether a variable should be retained in the model.

\section{Results}

Participants $(n=354)$ were predominantly male $(n=249$, $70 \%$ ), with a mean age of 47 years (Interquartile Range [IQR]: 38-55), and a median of 24 years of IDU (IQR: 13$35)$. Thirty-eight percent of participants $(n=135)$ reported ever providing injection initiation assistance, and 39\% $(n=137)$ reported ever having been enrolled in MAT. The proportion of MAT enrollment for males was $67.9 \%$ $(n=93)$ and $32.1 \%(n=44)$ for female and transgender participants. The majority of participants $(n=304,86 \%)$ reported having ever injected heroin.

As shown in Table 1, there was a significantly higher proportion of participants $\leq 30$ years old who reported ever providing injection initiation assistance compared with older participants aged $31-50$ and $\geq 51$ years $(69.0 \%$ vs. $37.7 \%$ vs. $32.9 \%$, Fisher's exact $p<0.01$ ).

As shown in Table 2, each year increase in age was associated with a decreased odds of ever providing injection initiation assistance (Wald $X^{2}=13.27$, degrees of freedom $[d f]=1, p<0.01)$, while reporting a higher number of years since first injection was associated with an increased odds initiating others (Wald $\chi^{2}=5.53$, $d f=1, p=0.02$ ). PWID reporting a history of MAT enrollment had significantly decreased odds of initiating others into injecting (Wald $\chi^{2}=4.04, d f=1, p=0.04$; see Table 2). Additionally, the inclusion of an interaction term in a separate multivariate model did not significantly impact the association between gender and a history of MAT enrollment $\left(\mathrm{X}^{2}=1.13, d f=1, p=0.29\right.$; data not shown).

\section{Discussion}

Along with its effectiveness in supporting the management of opioid use disorder [1-4], these preliminary results suggest that MAT enrollment may also be associated with a reduced risk that PWID initiate others into IDU. Specifically, results suggest that among PWID participants, a history of MAT enrollment was associated with a $38 \%$ reduction in the odds of having reported initiating others into IDU. This suggests a need to further explore potential pathways by which MAT enrollment may influence the risk that PWID provide injection initiation assistance. 
Table 1 Univariate analysis of factors potentially associated with ever providing injection initiation assistance among persons who inject drugs in San Diego, CA $(n=354)$

\begin{tabular}{clll}
\hline Variable & $\begin{array}{l}\text { Did not ever initiate } \\
\text { Others into injection } \\
(n=219)\end{array}$ & $\begin{array}{l}\text { Ever initiated others } \\
\text { into injection } \\
(n=135)\end{array}$ & P-value $^{a}$ \\
\hline Age & & & \\
$\leq 30$ & $9(31.0 \%)$ & $63(69.0 \%)$ & 0.001 \\
$31-50$ & $104(62.3 \%)$ & $52(32.9 \%)$ & \\
$\geq 51$ & $106(67.1 \%)$ & $34(34.7 \%)$ & 0.460 \\
Gender, $n=352^{b}$ & $3(60.0 \%)$ & \\
Female & $64(65.3 \%)$ & $96(38.6 \%)$ & \\
Transgender & $2(40.0 \%)$ & & 0.398 \\
Male & $153(61.5 \%)$ & $13(31.7 \%)$ & \\
Marital Status & & $122(39.0 \%)$ & \\
Married & $28(68.3 \%)$ & &
\end{tabular}

Ever been in prison

$\begin{array}{cccc}\text { No } & 103(60.2 \%) & 68(39.8 \%) & 0.585 \\ \text { Yes } & 116(63.4 \%) & 67(36.6 \%) & \\ \text { Years since first injection, } n=353^{\mathrm{b}} & & \\ \leq 5 \text { years } & 10(50.0 \%) & 10(50.0 \%) & 0.504 \\ \text { 6-10 years } & 30(61.2 \%) & 19(38.8 \%) & \\ >10 \text { years } & 179(63.0 \%) & 105(37.0 \%) & \end{array}$

Ever injected heroin

$\begin{array}{llll}\text { No } & 31(62.0 \%) & 19(38.0 \%) & >0.999 \\ \text { Yes } & 188(61.8 \%) & 116(38.2 \%) & \end{array}$

Ever injected cocaine

$\begin{array}{llll}\text { No } & 56(62.9 \%) & 33(37.1 \%) & 0.900 \\ \text { Yes } & 163(61.5 \%) & 102(38.5 \%) & \end{array}$

Ever injected meth

$\begin{array}{lll}\text { No } & 29(76.3 \%) & 9(23.7 \%) \\ \text { Yes } & 190(60.1 \%) & 126(39.9 \%)\end{array}$

Ever enrolled in MAT

$\begin{array}{lll}\text { No } & 128(59.0 \%) & 89(41.0 \%) \\ \text { Yes } & 91(66.4 \%) & 46(33.6 \%)\end{array}$

${ }^{a}$ Fisher's exact test; ${ }^{b}$ Change in sample size due to different number of observations available for each variable; MAT Medication-assisted Treatment

Table 2 Multivariate Logistic Regression to assess factors associated with ever providing injection initiation assistance in San Diego, CA

\begin{tabular}{lllll}
\hline Variable & AOR & $95 \% \mathrm{Cl}$ & P-value $(d f)$ & Test Statistic $^{a}$ \\
\hline Age & 0.94 & $0.91-0.97$ & $<0.01(1)$ & 13.27 \\
Years since first injecting & 1.04 & $1.00-1.07$ & $0.02(1)$ & 5.53 \\
Male gender & 1.18 & $0.72-1.92$ & $0.52(1)$ & 0.41 \\
Ever enrolled in MAT & 0.62 & $0.39-0.99$ & $0.04(1)$ & 4.04 \\
\hline
\end{tabular}

${ }^{a}$ Wald test in the multivariate logistic regression model; AOR Adjusted Odds Ratio, 95\% Cl 95\% Confidence Interval, $d f$ degrees of freedom, MAT Medication-assisted Treatment
In line with other studies, we also found that each year increase in age was associated with a decreased risk of providing injection initiation assistance $[16,17]$. However, in contrast to these studies we observed an association between a higher number of years since first injection and an increased risk of providing injection initiation assistance.

Multiple studies have reported on gender differences in injection initiation, including data suggesting that men are most often initiated by men comparted to women $[12-15,18]$. Additionally, data suggest that some genderresponsive programs may influence the capacity of PWID to engage with supplementary health services offered during MAT enrollment [11, 19-25]. However, the effect of a history of MAT enrollment on providing injection initiation assistance did not differ significantly between male and female participants in our sample. Further quantitative and qualitative studies are needed to more clearly delineate potential differences by gender with respect to injection initiation risk and uptake of MAT.

To our knowledge, this is the first study to investigate the potential impact of MAT enrollment on providing injection initiation assistance. As such, and due to the exploratory nature of this analysis, results should be interpreted cautiously. First, survey items assessing lifetime initiation of others into IDU were limited to the final follow-up of a 24-month observational cohort study, and we were therefore unable to identify the temporal ordering of the dependent and independent variables, and, as such, cannot confirm the direction of the causal association. It may be the case that both enrollment in MAT and avoiding the initiation of others into IDU are both proxy markers of increased capacity by participants to manage their opioid use and we note that this will be the subject of future longitudinal study from our group. Second, providing injection initiation assistance is a highly stigmatized behavior and likely resulted in under-reporting of this behavior [13, 26]. However, there is no reason to believe that differential underreporting occurred among PWID based on MAT enrollment history; thus, the effect of this bias is likely to be toward a null finding. Despite these limitations, this study provides preliminary evidence particular to opioid users of an association between MAT enrollment and the provision of injection initiation assistance that should be investigated in longitudinal study.

\section{Conclusions}

Given the harms associated with recent increases in opioid use across North America [1, 4], this study highlights the need to further investigate the potential impact of MAT as a preventive intervention to reduce not only the incidence of negative injection-related health outcomes experienced by opioid users but also incident cases of IDU initiation. 


\section{Abbreviations}

AIDS: Acquired Immune Deficiency Syndrome; AOR: Adjusted Odds Ratio; CA: California; Cl: Confidence Interval; DF: Degrees of Freedom; HCV: Hepatitis C Virus; HIV: Human Immunodeficiency Virus; IDU: Injection Drug Use; IQR: Interquartile Range; LRS: Likelihood Ratio Statistic; MAT: Medication-assisted treatment; NIDA: National Institute of Drug Abuse; PRIMER: Preventing Injecting by Modifying Existing Responses Study; PWID: People who Inject Drugs; USA: United States of America

\section{Acknowledgements}

The authors thank the study participants for their contribution to the research, as well as current and past STAHR-II/PRIMER researchers and staff. We would also like to thank the anonymous reviewers who helped improve this manuscript.

\section{Funding}

Dr. Mittal is supported by the Fogarty International Center of the National Institutes of Health (NIH) Award Numbers D43TW008633 and R25TW009343, UC San Diego Center for AIDS Research (CFAR) NIAID P30AI36214 and National Institute of Drug Abuse (NIDA) grant T32DA023356. Mr. Vashishtha is supported by NIH grant 1TL1TR001443. Dr. Garfein is supported by NIDA award R01DA031074. Dr. Strathdee is supported through a NIDA MERIT award R37DA019829. Dr. Werb is supported by a US NIDA Avenir Award (DP2-DA040256-01) and by a New Investigator Award from the Canadian Institutes of Health Research.

\section{Availability of data and materials}

The data used for this study is not publicly available. For further information on the data and materials used in this study, please contact the corresponding author.

\section{Authors' contributions}

DW, SAS, JCM and RG designed and implemented the survey. MLM, SS, SJ and DW designed the present analysis plan, conducted the statistical analyses, drafted the manuscript, and incorporated suggestions from all coauthors. All authors made significant contributions to the conception of the analyses, interpretation of the data, and drafting of the manuscript. All authors read and approved the final manuscript.

\section{Ethics approval and consent to participate}

The study was approved by the research ethics board at the University of California San Diego Human Research Protection Program. All participants provided written informed consent for study participation.

\section{Consent for publication}

Not applicable.

\section{Competing interests}

The authors declare that they have no competing interests.

\section{Publisher's Note}

Springer Nature remains neutral with regard to jurisdictional claims in published maps and institutional affiliations.

\section{Author details}

${ }^{1}$ Division of Infectious Diseases and Global Public Health, Department of Medicine, University of California San Diego, 9500 Gilman Drive, La Jolla, CA 92093-0507, USA. ${ }^{2}$ Division of Biostatistics and Bioinformatics, Department of Family Medicine and Public Health, University of California San Diego, 9500 Gilman Drive, La Jolla, CA 92093-0622, USA

\section{Received: 16 March 2017 Accepted: 26 September 2017}

\section{Published online: 03 October 2017}

\section{REFERENCES}

1. Office of the Surgeon General. Facing Addiction in America: The Surgeon General's Report on Alcohol, Drugs, and Health. Washington: US Dept of Health and Human Services; 2016. [cited 2016 Nov 16]. Available from: https://addiction.surgeongeneral.gov/surgeon-generals-report.pdf.

2. Substance Abuse and Mental Health Services Administration (SAMHSA). Medication-Assisted Treatment (MAT) [Internet]. SAMHSA; 2016 [cited 2017 Jun 20]. Available from: https://www.samhsa.gov/medication-assisted-treatment
3. Mattick RP, Breen C, Kimber J, Davoli M. Methadone maintenance therapy versus no opioid replacement therapy for opioid dependence. Cochrane Database Syst Rev. 2009;|8(3):CD002209.

4. Gowing L, Farrell M, Bornemann R, Sullivan L, Ali R. Oral substitution treatment of injecting opioid users for prevention of HIV infection. Cochrane Database Syst Rev. 2011;10(8):CD004145.

5. Werb D, Garfein R, Kerr T, Davidson P, Roux P, Jauffret-Roustide M, Auriacombe M, Small W, Strathdee SA. A socio-structural approach to preventing injection drug use initiation: rationale for the PRIMER study. Harm Reduct J. 2016 Sep 15;13(1):25.

6. Werb D, Buxton J, Shoveller J, Richardson C, Rowell G, Wood E. Interventions to prevent the initiation of injection drug use: a systematic review. Drug Alcohol Depend. 2013;133(2):669-76.

7. United Nations Office on Drugs and Crime. World Drug Report 2016. New York: United Nations publication; 2016. [cited 2016 Nov 16]. Available from: https://www.unodc.org/doc/wdr2016/WORLD_DRUG_REPORT_2016_web.pdf.

8. Degenhardt L, Whiteford HA, Ferrari AJ, Baxter AJ, Charlson FJ, Hall WD, et al. Global burden of disease attributable to illicit drug use and dependence: findings from the Global Burden of Disease Study 2010. Lancet. 2013; 382(9904):1564-74.

9. Garfein RS, Vlahov D, Galai N, Doherty MC, Nelson KE. Viral infections in short-term injection drug users: the prevalence of the hepatitis $C$, hepatitis $B$, human immunodeficiency, and human T-lymphotropic viruses. Am J Public Health. 1996;86(5):655-61.

10. Scott N, Caulkins JP, Ritter A, Dietze P. How patterns of injecting drug use evolve in a cohort of people who inject drugs. Trends and Issues in Crime and Criminal Justice. 2015;502:1.

11. Grella CE. From generic to gender-responsive treatment: Changes in social policies, treatment services, and outcomes of women in substance abuse treatment. J Psychoactive Drugs. 2008 Nov 1:40(sup5):327-43.

12. Goldsamt LA, Harocopos A, Kobrak P, Jost JJ, Clatts MC. Circumstances, pedagogy and rationales for injection initiation among new drug injectors. J Community Health. 2010;35(3):258-67.

13. Small W, Fast D, Krusi A, Wood E, Kerr T. Social influences upon injection initiation among street-involved youth in Vancouver, Canada: a qualitative study. Substance Abuse Treatment, Prevention, and Policy. 2009;4(1):1.

14. Bryant J, Bryant J, Treloar C, Bryant J, Treloar C. The gendered context of initiation to injecting drug use: evidence for women as active initiates. Drug and alcohol review. 2007 Jan 1;26(3):287-93.

15. Doherty MC, Garfein RS, Monterroso E, Latkin C, Vlahov D. Gender differences in the initiation of injection drug use among young adults. J Urban Health. 2000;77(3):396-414

16. Bluthenthal RN, Wenger L, Chu D, Quinn B, Thing J, Kral AH. Factors associated with initiating someone into illicit drug injection. Drug Alcohol Depend. 2014 Nov 1:144:186-92.

17. Bryant J, Treloar C. Initiators: An examination of young injecting drug users who initiate others to injecting. AIDS Behav. 2008 Nov 1:12(6):885-90.

18. Frajzyngier V, Neaigus A, Gyarmathy VA, Miller M, Friedman SR. Gender differences in injection risk behaviors at the first injection episode. Drug Alcohol Depend. 2007:89(2-3):145-52.

19. Greenfield SF, Brooks AJ, Gordon SM, Green CA, Kropp F, McHugh RK, Lincoln M, Hien D, Miele GM. Substance abuse treatment entry, retention, and outcome in women: A review of the literature. Drug Alcohol Depend. 2007 Jan 5;86(1):1-21.

20. Green CA, Polen MR, Dickinson DM, Lynch FL, Bennett MD. Gender differences in predictors of initiation, retention, and completion in an HMO-based substance abuse treatment program. J Subst Abus Treat. 2002 Dec 31;23(4):285-95.

21. Messina N, Grella CE, Cartier J, Torres SA. randomized experimental study of gender-responsive substance abuse treatment for women in prison. J Subst Abus Treat. 2010 Mar 31;38(2):97-107.

22. Jimenez-Treviño L, Saiz PA, García-Portilla MP, Díaz-Mesa EM, Sánchez-Lasheras F, Burón $\mathrm{P}$, et al. A 25-year follow-up of patients admitted to methadone treatment for the first time: mortality and gender differences. Addict Behav. 2011;36(12):1184-90.

23. Marsh JC, Cao D, D'Aunno T. Gender differences in the impact of comprehensive services in substance abuse treatment. J Subst Abus Treat. 2004:27(4):289-300

24. Haug NA, Sorensen J, Lollo N, Gruber V, Delucchi K, Hall S. Gender differences among HIV-positive methadone maintenance patients enrolled in a medication adherence trial. AIDS Care. 2005;17(8):1022-9. 
25. Chatham LR, Hiller ML, Rowan-Szal GA, Joe GW, Simpson DD. Gender differences at admission and follow-up in a sample of methadone maintenance clients. Substance Use \& Misuse. 1999;34(8):1137-65.

26. Wenger LD, Lopez AM, Kral AH, Bluthenthal RN. Moral ambivalence and the decision to initiate others into injection drug use: A qualitative study in two California cities. International Journal of Drug Policy. 2016 Nov 30;37:42-51.

Submit your next manuscript to BioMed Central and we will help you at every step:

- We accept pre-submission inquiries

- Our selector tool helps you to find the most relevant journal

- We provide round the clock customer support

- Convenient online submission

- Thorough peer review

- Inclusion in PubMed and all major indexing services

- Maximum visibility for your research

Submit your manuscript at www.biomedcentral.com/submit 